Original Article

\title{
STUDY TO EVALUATE SEVERE ADRS IN A TERTIARY CARE TEACHING HOSPITAL
}

\author{
A. R. MALAHAT ${ }^{*}{ }^{*}$, C. DEEPA LATHA ${ }^{2}$, SUDHAKAR K³ ${ }^{3}$, DEEPIKA BALOJU $^{4}$, G. VIJAYALAKSHMI ${ }^{5}$
}

1Post Graduate Department of Pharmacology Bhaskar Medical College Moinabad, 2,3Department of Pharmacology Bhaskar Medical College Moinabad, 4 Patient Safety Pharmacovigilance Associate, ADR Monitoring Centre Bhaskar Medical College, Moinabad, 5 Department of Pharmacology Bhaskar Medical College Moinabad

Email: dr.malahatjalal88@gmail.com

Received: 20 May 2017, Revised and Accepted: 22 Jul 2017

ABSTRACT

Objective: This study attempts to analyze the severe ADRs in a tertiary care centre and assess their seriousness, outcome, causality and severity. We emphasize on the need for reporting of ADRs by all healthcare professionals as it will reduce the burden of morbidity due to drugs and ensure better and more efficient healthcare. To analyse and evaluate the severe ADVERSE DRUG REACTIONs reported from various departments in a Tertiary care Teaching hospital.

Methods: It is a prospective observational study that was carried out over a period of 6 mo (from July 2016 to December 2016 ) to assess the percentage of severe adverse drug reactions reported to the Pharmacovigilance cell of a tertiary care teaching hospital. The data collected included patient's demographic details, presenting complaints, clinical diagnosis and details of the drug(s) prescribed. The data was analysed for causality (as per the WHO-UMC scale) and severity (as per Hartwig and Siegel scale).

Results: Out of 64 ADRs reported, 17 were serious. The majority of serious ADRs were categorized as probable (82.35\%), whilst $1(5.8 \%)$ was categorized as possible and $2(11.76 \%)$ as certain in nature. The criteria for the majority of serious ADRs were hospitalization (\%) followed by intervention to prevent permanent impairment or damage (\%).

Conclusion: The highest percentage of severe cases was reported with Antitubercular therapy (23.5\%) followed by analgesics (23\%) and anti epileptic agents (17.6\%).

Keywords: Pharmacovigilance, Causality, Severity, Adverse drug reactions

(C) 2017 The Authors. Published by Innovare Academic Sciences Pvt Ltd. This is an open access article under the CC BY license (http://creativecommons.org/licenses/by/4.0/)

DOI: http://dx.doi.org/10.22159/ijcpr.2017v9i5.22137

\section{INTRODUCTION}

Drugs are capable of causing immense comfort as well as irreparable harm to man. Harms caused by medicines are often described as adverse drug events and these can be due to either medication errors or adverse drug reactions [1]. While medication error is a broad term and points at an error which is in control of the health care professional or the patient, the World Health Organization (WHO) defines an adverse drug reaction (ADR) as "a reaction which is noxious and unintended, and which occurs in doses normally used in human for prophylaxis, diagnosis, or therapy of disease, or for the modification of physiological functions [2]

The Government of India established National Pharmacovigilance Program in November 2004, after which the Pharmacovigilance program of India (PvPI) was launched in 2010. This programme aims at establishing the habit of ADR notification by health care workers all over India.

The purpose of ADR monitoring is to help ensure that patients are entitled to safe and effective medicines and also to generate ADR data which is crucial for understanding the purpose of pharmacovigilance and for educating the health care providers about this discipline.

The criteria for serious adverse drug reactions (serious ADRs) have been specified by the WHO and includes any untoward medical occurrence at any dose that results in death, life-threatening, requires or prolongs hospitalization, or results in persistent or significant disability or incapacity [3].

The overall incidence of serious ADRs in the US between 1966 to 1996 was $6.7 \%$ and a number of fatal ADRs were $0.32 \%$ of hospitalized patients. Serious ADRs occured in $10-20 \%$ of hospitalized patients making these reactions between the fourth and sixth leading cause of death [4].
In this study we attempt to analyze the serious ADRs in a tertiary care centre and assess their seriousness, outcome, causality and severity.

In a resource limited country like India, the concept of ADR monitoring and the practice of ADR reporting is yet to catch up. Our study emphasizes on increasing numbers of serious ADRs and the need to improve models for patient care benefit in intensive care units by training pharmacovigilance cell members to collaborate with hospital consultants and help reduce mortality due to serious ADRs.

\section{MATERIALS AND METHODS}

A prospective observational study was carried out at ADR monitoring centre of Bhaskar General Hospital from July 2016 to Dec 2016 after obtaining Permission from Institutional Ethical Committee of the hospital.

64 suspected ADRs were collected using the ADR notification form (yellow form) and CDSCO form (red form). These were analysed for seriousness using Hardwick Seigal scale and causality assessment was done using WHO-UMC scale.17 out of 64 ADRs were reported to be serious.

ADRs were diagnosed by the treating consultants, and relevant details of each ADR were collected in spontaneous ADR reporting form(yellow form) The details were then fed into the CDSCO form(red form) and sent to the National Coordinating Centre via Vigiflow software.

ADRs were reported from Departments of Dermatology, Gynaecology, Haematology, Medicine, Ophthalmology, Pediatrics, Psychiatry, and Pulmonology.

The collected information included patient's initial, age, gender, reporting department of the hospital, description of the reaction, 
duration of the reaction, the name of the suspected drug causing the reaction, concomitant drug if any, and outcomes.

Serious ADRs were identified as per the WHO-UMC criteria and analyzed to find the time relationship with the initiation of drug treatment, causal drug group, and body system as per system organ class (SOC). Causality assessment was done using the WHO-UMC scale [5]. While Severity was assessed using modified Hartwig and Siegel scale [6].

The outcome of the patients with ADR was recorded as fatal, fully recovered (patient fully recovered during the study period), recovering (patient recovering, but not fully recovered during the study period) and unknown (insufficient information and not documented)

\section{Type of study}

\section{Prospective observational study}

\section{Study design}

The data will be collected from the prescriptions of patients suffering with ADRs by the respective consultants in the ADR reporting form and will include Patient particulars, history, diagnosis, drugs-the dosage, frequency, and duration of treatment, comorbid conditions, suspected drug that caused ADR, description of the ADRs, details on hospital stay, concomitant drugs, generic or brand prescription information. The CDSCO form is then duly filled at the ADR monitoring centre and with access to the yellow form, the data is will be analysed tabulated, and statistical analysis will be carried out.

\section{Selection criteria}

\section{Inclusion criteria}

All the suspected ADRs that may be due to the medications, both prescribed and over the counter, taken by patients either as inpatients or outpatients, that were ultimately documented.

\section{Exclusion criteria}

The use of the alternative system of medicines such as Ayurveda, Homeopathy, Unani, etc. was excluded.

All mentally retarded, drug addicted, and unconscious patients were also excluded from the study.

Patients admitted due to alcohol or drug abuse, a suicide attempt or incoherent patients with unreliable data were excluded.

\section{Statistical analysis}

Data entry and analysis was done using Microsoft Excel 2010 version. Data was presented in percentages and proportions. Bars diagrams and pie charts were used to depict percentages.

\section{RESULTS}

64 patients were reported to experience ADR at BGH during the study period. Of these, $17(26.5 \%)$ were serious and $47(73.4 \%)$ were non-serious as per the Hartwig Seigal scale

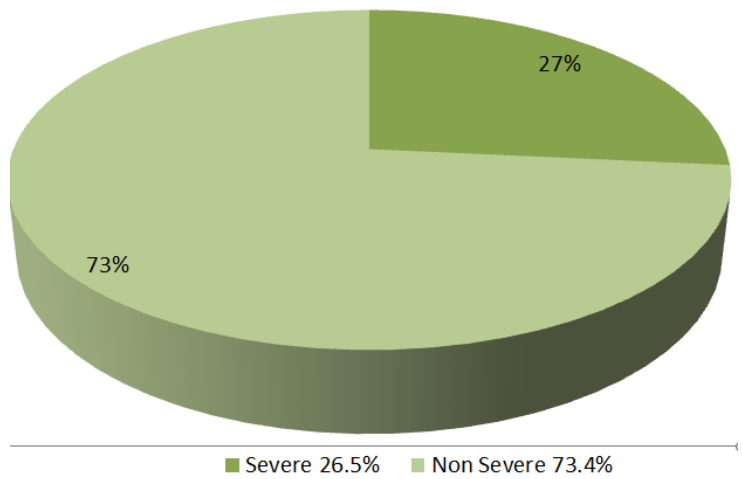

Fig. 1
Fig. 2 shows the distribution of ADRs in different age groups, both male and female. The mean age of patients with serious ADRs was $49 \mathrm{y}$. There were no severe ADRs in the pediatric age group.

\section{males females}

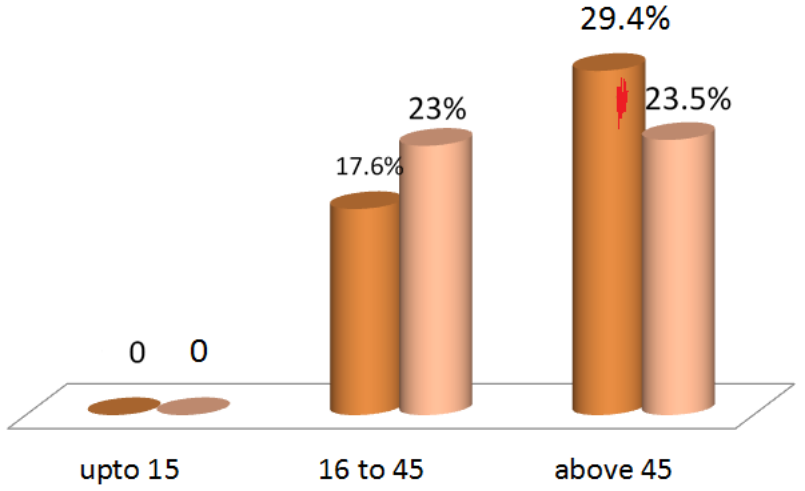

Fig. 2: The severe ADRs, 9 patients (52.9\%) were females and $8(47 \%)$ were males with a male: female ratio of $1: 0.88$

Most of the severe reactions were among the age group 40-60 y and it was observed that Polypharmacy is ubiquitous for the development of ADRs.

\section{Causality Assessment}

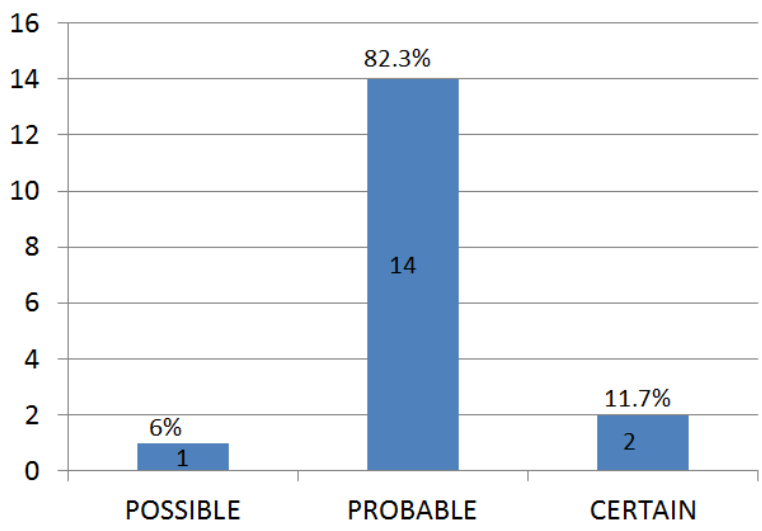

Fig. 3

Fig. 3 shows the percentage of cases reported to be possible, probable and certain. The causality assessment revealed that most of the ADRs belonged to "probable" category $(14,82.3 \%)$ followed by "certain" category $(2,11.7 \%)$.

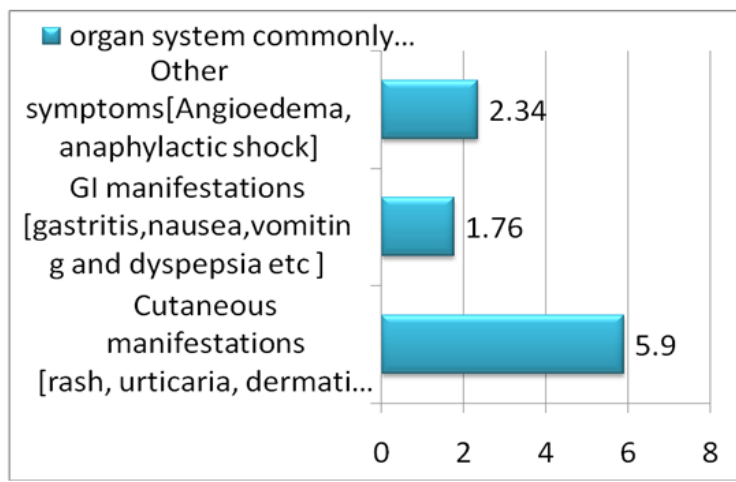

Fig. 4: Shows the various ADRs reported system wise 
Cutaneous manifestations which included rash, urticaria, dermatitis, Steven Johnson syndrome, Toxic epidermal necrolysis etc were most common ADRs with an incidence of 58.8\% and these were most commonly due to antiepileptic agents like Phenytoin and Carbamazepine.

The next organ system commonly involved was a gastrointestinal system which included gastritis, nausea, vomiting and dyspepsia etc accounting for $17.6 \%$ of total ADRs. and analgesics were the most common offending agents here.

$23.53 \%$ of the severe ADRs were due to DOTS-ATT specifically Rifampicin, $23 \%$ due to analgesics with paracetamol one of the active ingredients and $17.65 \%$ were due to anti epileptic agents like Phenytoin and CBZ.

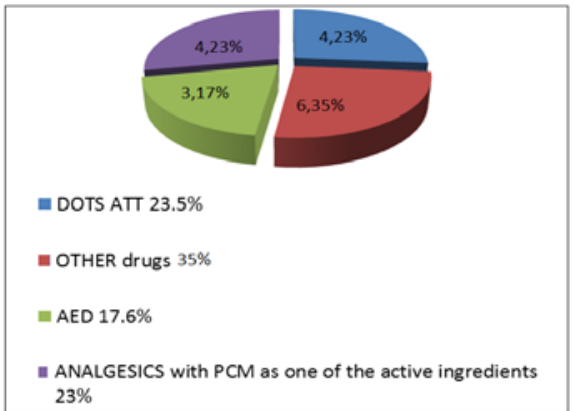

Fig. 5: Shows various ADRs classified based on causative drug

Table 1: Clinical pattern of serious ADRs

\begin{tabular}{|c|c|c|}
\hline Clinical presentation & Suspected drug & Number of severe ADRs (\%) \\
\hline \multirow[t]{2}{*}{ Steven Johnsons Syndrome } & Carbamazepine & $1(5.8)$ \\
\hline & Phenytoin & $1(5.8)$ \\
\hline \multirow[t]{6}{*}{ Severe Urticaria } & Phenytoin & $1(5.8)$ \\
\hline & DOTS & $2(11.7)$ \\
\hline & Paracetamol, & $1(5.8)$ \\
\hline & Amoxacillin+Clauvanic acid & $2(11.7)$ \\
\hline & Ceftriaxone & $1(5.8)$ \\
\hline & Olmesartan & $1(5.8)$ \\
\hline Gastritis, Nausea, Vomiting, & Rifampicin & $2(11.7)$ \\
\hline \multirow[t]{2}{*}{ Syncope } & Paracetamol & $2(11.7)$ \\
\hline & Aceclofenac+Paracetamol & $1(5.8)$ \\
\hline Generalised Edema and shock & Azithromycin & $1(5.8)$ \\
\hline Fever with chills, falling BP progressing to Shock & Inj. Iron-Sucrose for anemia & $1(5.8)$ \\
\hline
\end{tabular}

A maximum number of Severe ADRs were reported from the Dept of General Medicine, followed by Departments of Pulmonology and Skin., All cases were admitted in the ICU of BGH and treated until recovery.

\section{DISCUSSION}

According to a meta-analysis review of 39 prospective studies carried out in the US from 1966 to 1996, the overall incidence of serious ADRs was $6.7 \%$ and of fatal ADRs was $0.32 \%$ of hospitalized patients [4] Similarly, it has been estimated that $5 \%$ of all hospital admissions in the EU are caused by ADRs, $5 \%$ of hospitalized patients will experience an ADR during their hospital stay, and that ADRs cause 197,000 deaths annually throughout the EU [7]. A study by Ramesh $e t$ $a l$. in India carried out in a tertiary referral centre in India showed that admissions due to ADRs accounted for $0.7 \%$ of total admissions and deaths due to ADRs accounted for $1.8 \%$ of total ADRs [8]

In this study, spontaneously reported adverse drug reactions were evaluated for a period of $6 \mathrm{mo}$, with emphasis on serius ADRs. Of the total adverse drug reactions reported, 17(26.5\%) were serious. This shows that severe ADRs are a significant proportion of the ADR burden which is supported by a study conducted by Lukshmy M Hettihewa. et al. [9] who reported in their study that severe adverse drug reactions were $31 \%$ of all ADRs reported.

It was observed that adverse drug reactions were more commonly reported in elderly (above $45 \mathrm{y}$ ) due to polypharmacy, as more drugs were being used in this age to address other comorbid conditions.

The male and female ratio was found to be 1:0.88, with the nearly equal incidence of males and females. This is in contrast with the study by Sarminder Kaur et al. [10], in which preponderance of ADRs was seen in female subjects as compared with males. $27.9 \%$ of females enrolled in their study suffered from ADR as compared with $15.8 \%$ of enrolled males.

Systems most commonly affected were dermatological in 58.9\% of patients, gastrointestinal in $17.6 \%$ of patients. The results were comparable with an international study conducted by Suh et al. [11], which revealed that the system most badly affected were the dermatological and gastrointestinal systems.
The drug class mostly associated with ADR were anti tubercular antibiotics and NSAIDs, both accounting for $23 \%$ of cases each, followed by anti epileptic drugs in $17.6 \%$ of patients in the present study. Murphy and Frigo developed and implemented an ADR reporting program in Loyola University Medical Center, Chicago and their study revealed that the most common adverse reactions were rash; and antibiotics were the most commonly implicated drug class [12]. Our results were also comparable with other studies like one done by Classen et according to whom NSAIDs are implicated in the majority of ADRs [13].

\section{CONCLUSION}

We conclude that Anticonvulsants, Analgesics and Antimicrobials are responsible for most of the ADRs in this study.

In view of the increasing percentage of severe ADRs being reported, it would be helpful if ADR monitoring centre members are given basic training in monitoring and treating severe ADRs.

\section{ACKNOWLEDGEMENT}

I would like to thank Dr. Deepika Baloju, Pharmacovigilance cell associate, Bhaskar General Hospital for assisting me in procuring the data for this study. I am immensely thankful to Dr. C Ceepalatha, Associate Professor, Dept of Pharmacology, Bhaskar Medical College, for helping me and guiding me in every step throughout this study. I would also like to thank Dr. G. Vijaya Lakshmi, Professor and Head, Department of Pharmacology, BMC for her continuous encouragement and support.

\section{CONFLICT OF INTERESTS}

Declare none

\section{REFERENCES}

1. Current status of the monitoring of medication practice david cousins. Am J Health-Syst Pharm 2009;66(Suppl 3):S49-56. 
2. World Health Organization. Safety of medicines-a guide to detecting and reporting adverse drug reactions-why health professionals need to take actions. Geneva: World Health Organization; 2002.

3. Edwards IR, Aronson JK. Adverse drug reactions: definitions, diagnosis, and management. Lancet 2000;356:1255-9.

4. Lazarou J, Pomeranz BH, Corey PN. Incidence of adverse drug reactions in hospitalized patients: a meta-analysis of prospective studies. JAMA 1998;279:1200-5

5. The Use of the WHO-UMC System for Standardised Case Causality Assessment. Available from: http://www.WHOUMC.org/graphics/4409.pdf. [Last accessed 12 Feb on 2011]

6. Hartwig SC, Siegel J, Schneider PJ. Preventability and severity assessment in reporting adverse drug reactions. Am J Hosp Pharm 1992;49:2229-32.

7. European Commission. Proposal for a regulation amending, as regards pharmacovigilance of medicinal products for human use. Regulation (EC) No 726/2004. Impact assessment; 2008 Available from: http://ec.europa.eu/health/files/pharmacos/ pharmpack 12_2008/pharmacovigilance-ia-vol1_en.pdf. [Last accessed 03 Sep 2014].

8. Ramesh M, Pandit J, Parthasarathi G. Adverse drug reactions in a South Indian hospital-their severity and cost involved. Pharmacoepidemial Drug Saf 2003;12:687-92.
9. Lukshmy M Hettihewa. Bashinie Sirisena Causality. Assessment and the severity of adverse drug reactions (ADR) actively detected in hospital inpatients in a tertiary care hospital, Sri Lanka. Prospective observational survey. Asian J Res Biol Pharm Sci 2014;2:1-10.

10. Sharminder Kaur, Vinod Kapoor, Rajiv Mahajan, Mohan Lal, Seema Gupta. Monitoring of incidence, severity, and causality of adverse drug reactions in hospitalized patients with cardiovascular disease. Indian J Pharmacol 2011;43:22-6.

11. Suh DC, Woodall BS, Shin SK, Hermes-De Santis ER. Clinical and economic impact of adverse drug reactions in hospitalized patients. Ann Pharmacother 2000;34:1373-9.

12. Murphy BM, Frigo LC. Development, implementation, and results of a successful multidisciplinary adverse drug reaction reporting program in a university teaching hospital. Hosp Pharm 1993;28:1199-240.

13. Classen DC, Pestotnik SL, Evans RS, Lloyd JF, JP Burke. Adverse drug events in hospitalized patients. Excess length of stay, extra costs, and attributable mortality. JAMA 1997;277:301-6.

\section{How to cite this article}

- AR Malahat, C Deepa Latha, Sudhakar K, Deepika Baloju, G Vijayalakshmi. Study to evaluate severe ADRS in a tertiary care teaching hospital. Int J Curr Pharm Res 2017;9(5):55-58. 